\title{
A Reliable Wireless System for Water Quality Monitoring and Level Control
}

\author{
Hyder Khaleeq ${ }^{\dagger}$, Ali Abou-ElNour, and Mohammed Tarique \\ Department of Electrical Engineering \\ Ajman University of Science and Technology \\ P.O. Box 2202, Fujairah \\ United Arab Emirates \\ E-mail: m.tarique@ajman.ac.ae
}

Received: July 09, 2016

DOI: 10.5296/npa.v8i3.9719
Accepted: October 8, $2016 \quad$ Published: October 30, 2016

URL: http://dx.doi.org/10.5296/npa.v8i3.9719

\begin{abstract}
With the ever increasing growth in population water quality monitoring has become a critical issue in the recent years. Water quality monitoring is very important for aquaculture, waste water management, drinking water treatment, water distribution system, and other environmental applications. Recently numerous researchers have been initiated to build wireless system for water quality monitoring (WSWQM). The two fold objectives of WSWQM are (a) monitoring water quality from a remote location with minimum supervision, and (b) initiating immediate corrective actions to maintain the required water quality standard. In this paper we present a system model for WSWQM. In this system we integrate sensors, transmitters, receivers, myRIO microcontroller, and IEEE 802.11 Wi-Fi technology. The sensors generate water quality data including $\mathrm{pH}$, conductivity, and temperature. The real-time data are then sent wirelessly to a local control unit for analyzing, recording, and displaying. The system is also able to send alarm messages automatically to a remote management center when water quality falls below the required standard. In order to ensure high accuracy and reliability we use industry standard sensors and instrument to implement this system.
\end{abstract}

Keywords: Water, quality, Wi-Fi, sensors, wireless, pH, conductivity, WSN, WSWQM 


\section{Introduction}

High quality water is very important for drinking as well as for domestic usages. It is also important for power generation, food production, fisheries, and recreational activities. Polluted water can cause devastating effects on the public health. It may even can cause disease outbreaks. Hence, high quality water is important to support public health as well to promote socioeconomic development of a country [1]. Some of the alarming facts about the water are worthwhile to mention here: (a) around four million people die each year from water related diseases, (b) a child dies from water-related diseases in every 90 seconds, (c) one out of ten people does not have access to safe water, and (d) women and children spend 125 million hours a day collecting pure water in the underdeveloped countries [2]. The crisis for quality water has been listed as the top global risk by the World Economic Forum in January 2015 [3]. Poor quality water is now the world's biggest health risk and is a threat for public health.

Water pollution occurs mainly for two reasons (a) biological contamination, and (b) physicochemical contamination. Biological contamination occurs due to the ingestion of water contaminated by human or animal fasces. Biological contamination can be prevented by a series of treatment steps and by proper management of water distribution system. Physicochemical contamination arises from the chemical constituents after prolonged periods of exposure. In this case the water becomes undrinkable owing to unacceptable taste, odor, and appearance. The physicochemical contamination can be prevented by strictly monitoring and maintaining the chemical constituents of water at an acceptable limit.

The contamination of water has been linked to waterborne and water-related diseases. The contamination of water in distribution system mainly caused by inadequate operation, maintenance, and quality control. In addition, stresses on distribution system exacerbate the problem. These stresses are caused by rapid urbanization, population growth, and aging infrastructure.

In practice water quality is monitored by manually collecting samples from sites and by doing analysis in the lab. The water quality data are then recorded manually in computer or on paper. This technique of quality testing and recording is always exposed to human error. It also needs a lot of man hours for record keeping. In addition, there is a time lag between the detection of water quality problem and corrective actions taken. During this time lag the poor quality water continues polluting the existing distribution system. Keeping all these limitations in mind we present a wireless water quality monitoring system in this paper.

In the present work, we introduce a cost-effective water quality monitoring system using conventional sensors and Wi-Fi network. The basic components of our systems are hardware sensing circuits, interface circuit, and wireless system. We have developed software for monitoring and controlling unit. This unit is responsible for monitoring, controlling, and recording the water quality data. The hardware sensor circuits generate the calibrated output voltages, which are proportional to the variations in the measured water quality parameters. A 
wireless communication system has been integrated with our present system for handling data from a remote location. To implement wireless transmission of data we use National Instruments' myRIO and ZigBee technology.

Now-a-days, ZigBee based wireless solutions have drawn considerable attentions of the researchers in designing wireless monitoring and controlling systems. An excellent survey about ZigBee and their current applications can be found in [4]. We have selected myRIO controller to implement the wireless part of the system. The wireless communication system has been integrated with the sensor circuits, interface circuit, and software. The hardware sensor circuits generate water quality data that are collected by myRIO microcontroller. The data received by myRIO microcontroller are latched to a computer for further data recording, monitoring, and processing. The Wi-Fi technology has been used for this purpose. For system implementation we use LabVIEW software from National Instruments. The LabVIEW is an industrial standard and user friendly software. Moreover, it supports an easy graphical user interface for instrumentation and control. We developed a program in LabVIEW that continuously accepts transmitted data from the real time monitoring circuits. Our proposed wireless water quality monitoring system (a) reduces the system cost considerably, and (b) provides useful and continuous monitoring capabilities. The obtained results from the water quality monitoring system provide full details of spatial and temporal variations of different water quality parameters.

The rest of the paper is organized as follows. Some related works have been presented in section 2. In section 3 the system model has been explained. The system calibration and data analysis are presented in section 4 . The paper is concluded with section 5. Some future works have been presented in section 6 .

\section{Related Works}

Water is considered as a universal solvent. Various chemicals, dissolved in water, affect the attributes of water quality. In order to ensure quality of water these chemicals should be maintained at appropriate levels depending on the applications. Even water quality varies widely for the same application. Water quality is determined by different parameters including temperature, salinity, $\mathrm{pH}$, DO (dissolved oxygen), ammonia, nitrite/nitrate, hardness, alkalinity, and turbidity. Most of the water quality monitoring systems have been designed to monitor and control all or some of these parameters. In order to ensure quality wireless system for water quality monitoring (WSWQM) has been proposed for many applications. The main advantages of WSWQM are as follows: (a) it can monitor water quality without manual supervision, (b) it can keep records of water quality parameter for 24 hours a day, and (c) it can send data wirelessly to a remote monitoring station. Many works have been done in this field. We would like to mention here some of them that are directly related to our work.

An eco-friendly fish cultures using IT technology has been proposed in [5]. In this work 
water quality data such as temperature, DO, and salinity are acquired through sensors. The data are then transferred through a mobile terminal to a remote location for analysis. If the water quality data go beyond normal ranges the system sends immediate alarm message to a user. In addition, acquired data are analyzed to make predictions about sudden changes in the environment and disease outbreaks.

A similar work has been presented in [6]. In this paper, a water quality monitoring system has been designed to monitor the aquaculture farm's environment. Sensor Data Logger is the core part of the system. The monitoring system is able to provide data that can be accessed ubiquitously either from the internet or from the mobile phones.

Wireless RF and GSM based water monitoring system has been presented in [7]. The presented system can measure and publish water quality parameters such as temperature, and DO content online. These data are then stored in a computer. The system has also been designed to control an oxygen-increasing machine. This machine is able to maintain oxygen level in the water. The test result shows the system can monitor and control the water quality.

An intelligent system to monitor water quality from a remote location via SMS has been presented in [8]. The system can monitor and record real-time data of two water quality parameters namely $\mathrm{pH}$ and DO levels. The related data are reported through centralized station using GSM network through SMS.

To monitor water quality for prawn farming pond a wireless system has been presented in [9]. The proposed system uses wireless sensors for detecting water quality parameters namely $\mathrm{pH}$, temperature, and DO. The system uses SMS technology to deliver alert to the farmers upon detection of poor water quality. The system prototype has been developed based on the surveyed data. The results, acquired through the usability testing, imply that the system is able to meet the user's requirements.

A wireless sensor network (WSN) based water monitoring system has been proposed in [10]. The system has been designed and implemented based on ZigBee based wireless technology. The main features of the system are low cost, easy ad hoc installation, easy handling, and easy maintenance. The system uses a high power ZigBee based technology together with the IEEE 802.15.4 compatible transceiver. The system also allows easy customization. To evaluate reliability and effectiveness the system has been field tested. The results show that the system can monitor water quality with a high accuracy in a cost effective way.

A similar real-time water quality monitoring system, powered by solar and supported by a WSN technology, has been presented in [11]. The system architecture is based on sensor nodes and a base station. The sensor nodes are connected to the base station using ZigBee. Data collected by various sensor nodes include $\mathrm{pH}$, turbidity, conductivity, salinity, and temperature. The data are then sent via WSN to a base station. Data collected from a remote 
site are then analyzed at the base station. The system is environmental friendly because of the solar power supply. The other advantages include low power consumption, and flexibility. Hence the system can be deployed at a remote site with minimum supervision and maintenance.

A low-cost wireless water quality monitoring system has been presented in [12]. The proposed system allows users to monitor the quality of water at higher spatial resolution for an extended period of time. The system also helps to understand the behavior of aquatic animals relative to water pollution using data analysis. The results show that the system is able to monitor water quality reliably provided proper calibration is done.

A new wireless sensor based water environment monitoring system has been presented in [13]. The system consists of three parts namely (a) data monitoring station, (b) data base station, and (c) remote monitoring station. This system is designed for monitoring water in reservoirs, lakes, rivers, swamps, and shallow or deep ground waters. The system has been designed to monitor two water quality parameters namely temperature and $\mathrm{pH}$. The system is able to measure water temperature ranges from 0 to $80^{\circ} \mathrm{C}$ with an accuracy of $\pm 0.5^{\circ} \mathrm{C}$. It also measures $\mathrm{pH}$ value ranges from 0 to 14 with an accuracy of $\pm 0.05 \mathrm{pH}$ units.

Another solar powered water quality monitoring system has been designed and fabricated in [14] to monitor the quality of water in coastal regions. A self-organizing sensor network transmits water quality data to a base station via flooding routing protocol. The system consists of water quality sensor module that can measure $\mathrm{DO}, \mathrm{pH}$, conductivity, turbidity, depth of water, and temperature. The system has been made energy efficient by conserving the energy of field servers through query process.

A water quality monitoring system using WSN technology and powered by solar panel has been presented in [15]. The system architecture is constituted by several distributed sensor nodes and a base station. The nodes and base station are connected using WSN technology. The system also uses sensor nodes powered by solar cell. Data collected by various sensors in the node side such as $\mathrm{pH}$, turbidity, and oxygen density are sent via WSN to the base station for further analysis. The system reduces carbon emission due to solar power.

An in-situ on-line monitoring of water distribution system named Waterwise has been presented in [16]. The system facilitates efficient management and operation of water distribution system. In addition to water quality monitoring the system can also detect and localize pipe failures too. The WaterWiSe manages and analyses data from a network of intelligent wireless sensor nodes. The system continuously monitors hydraulic, acoustic, and water quality parameters. Moreover, the WaterWiSe also supports many applications including (a) dynamic prediction of water demand and hydraulic state, (b) online detection of events such as pipe bursts, and (c) data mining for identification of longer-term trends. 
In this paper we also present a WSWQM system that is able to monitor the water quality 24 hours a day in an efficient and reliable way. We integrate a wireless system with our system so that the water quality can be monitored and corrective actions can be taken from a remote location. The main features of our system are as follows:(a) the system is designed to accept all linear and nonlinear outputs from sensor circuits, (b) the system hardware can accept inputs from different sensor circuits, (c) the programming environment is flexible to generate all required reports based on the customer requirements, (d) the system can be used as a standalone or can be grid connected to a central monitoring units, and (e) the system can be connected to a Wi-Fi infrastructure network.:

\section{System Model}

The aim of the project is to monitor and collect water quality data such as $\mathrm{pH}$, conductivity, and temperature wirelessly in real time environment. Our system consists of two subsystems namely (a) wireless system for automatic water quality monitoring, and (b) wireless system for automatic water tank level control. The system block diagram is shown in Figure1.

Water quality monitoring sensors send data related to water quality as input signals to the system. The microcontroller NI myRIO processes these input signals and produces the output signals. The microcontroller NI myRIO has Wi-Fi connectivity in order to send data to a remote location labelled as Control and Monitoring unit as shown in Figure 2. The system can also control water level in a tank. In order to control the water tank level some additional digital input signals are generated by the tank level switches. The microcontroller processes these digital input signals and produces digital output signals that are used to control the water pump.

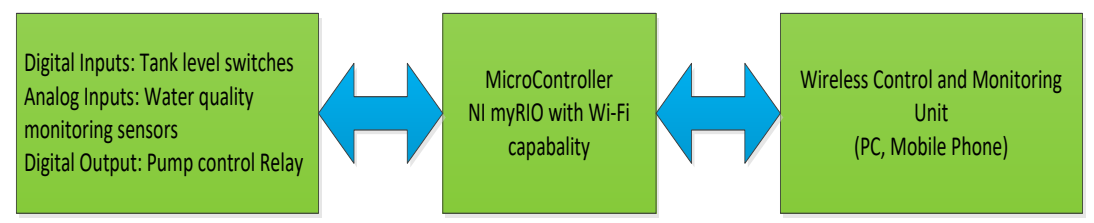

Figure 1. The system block diagram.

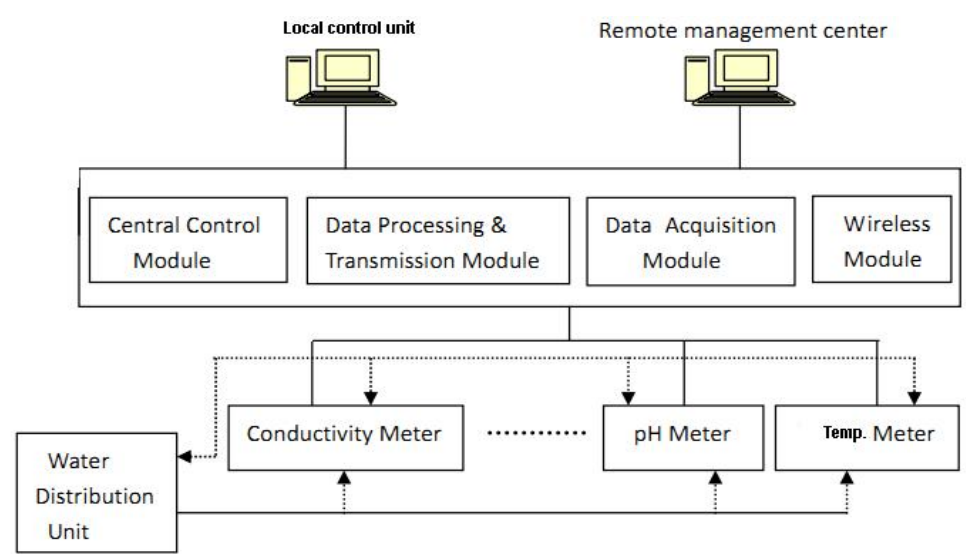

Figure 2. The water quality monitoring system diagram [16]. 
The other two key elements of the system are local control unit and remote management center. The detail architecture of the local control unit and remote management center are shown in Figure 3. We adopted this architecture based on a similar system presented in [16]. The automatic water tank level control is implemented by using two magnetic level switches as shown in Figure 3. The pump starts automatically when the water level in the tank is below some specified level and the pump stops when the water level in the tank is above some specified level. The low and high level switches are connected to digital input DIO1 and DIO2 of the myRIO. The digital output DIO5 is used to switch "on" and "off” the pump. To reduce load on output terminal DIO5 we use NPN2221A transistor to control the relay that operates the pump. We also use the same two magnetic level switches to indicate the water level in the tank. A submersible pump with 12 VDC supply is used to fill the tank. To reduce cost and simplify the system design the power for the control circuit is supplied from the myRIO. The switches and control relay are operating with 5V DC supply taken from the myRIO. The complete wiring diagram for water quality monitoring and automatic water tank level control system in shown in Figure 3.

In order to monitor the physical and chemical properties of water we use three different sensors to measure conductivity, $\mathrm{pH}$, and temperature. A number of water quality monitoring sensors are available from a number of manufacturers. Among them HACH LANG is the manufacturer of the most reliable and accurate sensors that are used in the industry. To achieve a high level of accuracy we use HACH LANG pH, conductivity, and temperature sensors in our system. Each sensor is equipped with a HACH LANG SC60 transmitter. These sensors are factory calibrated and can be verified and calibrated on site using standard buffer solution from the manufacturer. The $\mathrm{pH}$ buffer solutions of 4.0 and 7.0 are used to calibrate $\mathrm{pH}$ sensor. The buffer solution $2000 \mu \mathrm{S}$ is used to calibrate the conductivity sensor. These sensors produce data that are collected and processed by SC60 transmitters and transferred to the myRIO microcontroller for further processing as shown in Figure 4.

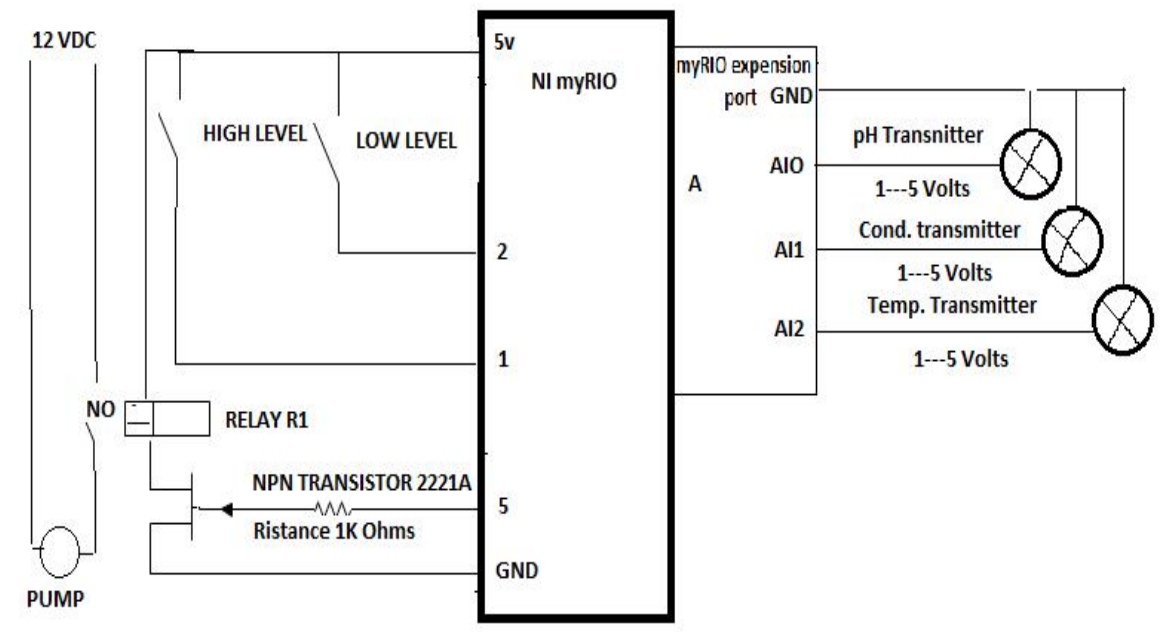

Figure 3. The wiring diagram for water quality monitoring and tank level control. 
The myRIO is a compact microcontroller with Wi-Fi IEEE 802.11 wireless connectivity. It has reconfigurable digital and analog inputs and outputs. The number of inputs and outputs can be modified according to user's requirements. The myRIO microcontroller collects the data sent by the sensors and transfers wirelessly to a LabVIEW program for further monitoring and analysis. These data are displayed and recorded in excel sheets used by a LabVIEW program that we have developed for this project. The front panel of the LabVIEW program is shown in Figure 5. The water quality data is then transferred to remote location and displayed on mobile device as shown in Figure 6.

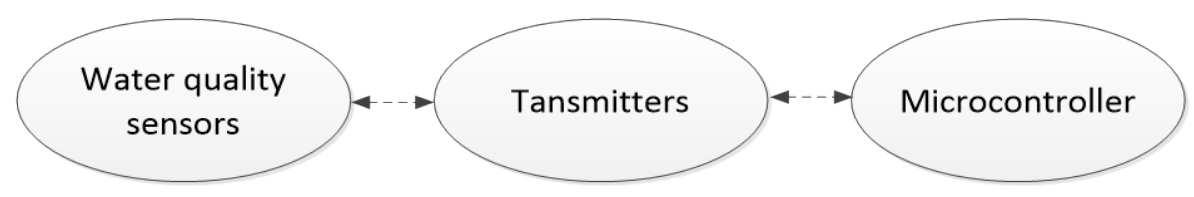

Figure 4. Water quality monitoring hardware block diagram

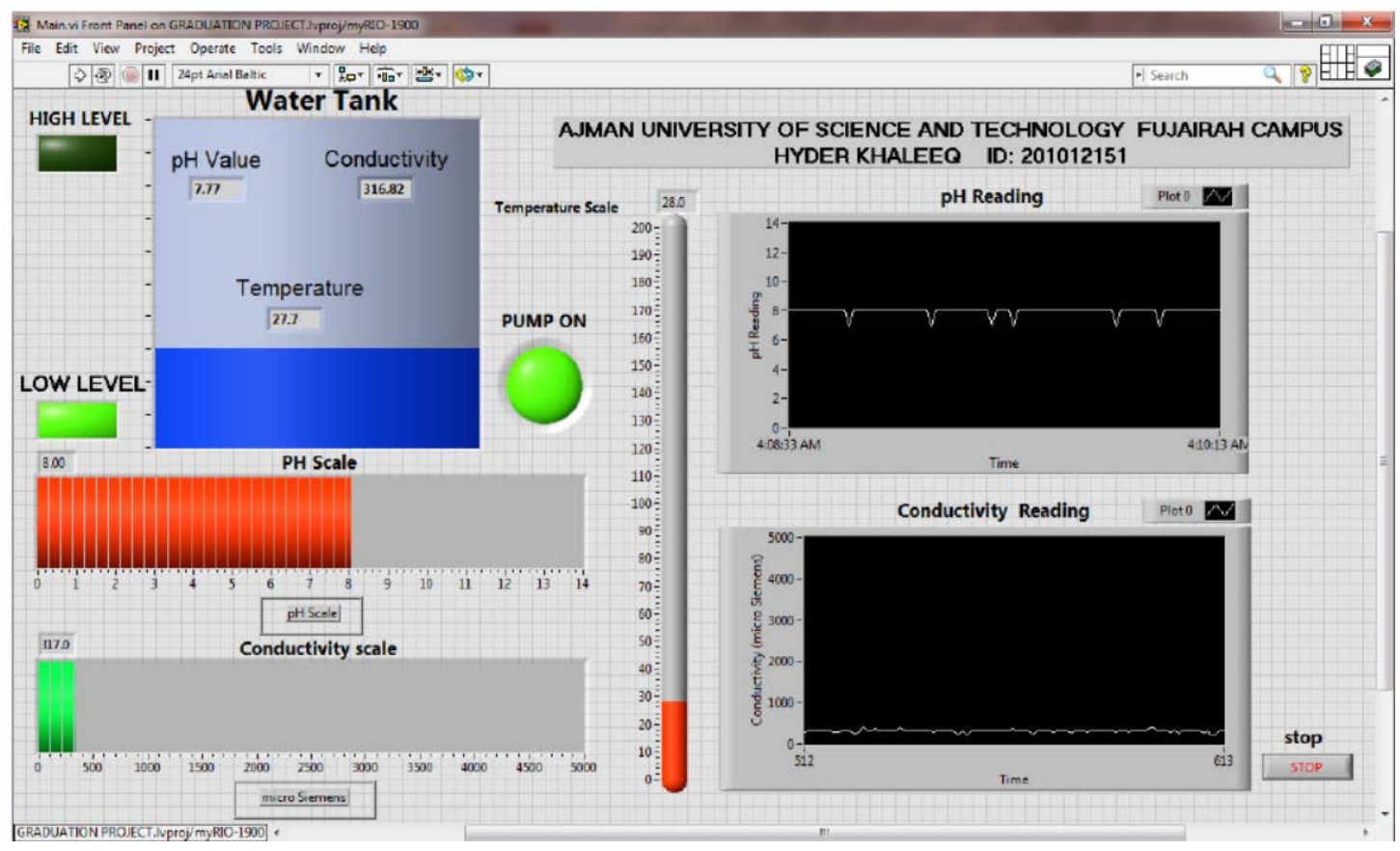

Figure 5. The LabVIEW Front panel of wireless system for water quality monitoring

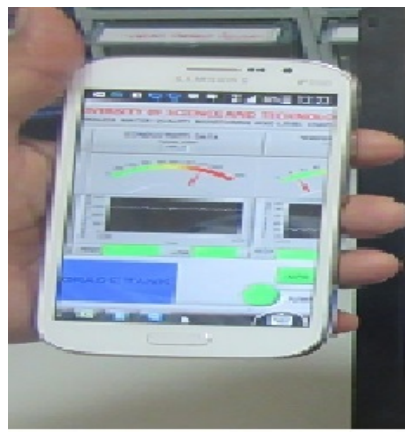

Figure 6. The water quality data displayed on a mobile device 
The front panel of the LabVIEW program displays the data related to conductivity, $\mathrm{pH}$, and temperature. The data are presented on scales as well as in graphs as shown in Figure 5. The level of the water tank is also available in the front panel. The 'Low Level' and 'High Level' indicators on the display menu are shown 'green' under normal condition. When this state changes, the indicators are shown by 'red'. The level control is done according to the following algorithm. When the water level in the tank becomes low the pump starts automatically to fill up the tank. On the other hand, when the water level becomes high, the pump stops. The status of the pump (i.e., running and stalling) is also displayed in the front panel with red and green color respectively. The LabVIEW block diagram of level control system is depicted in Figure 7.

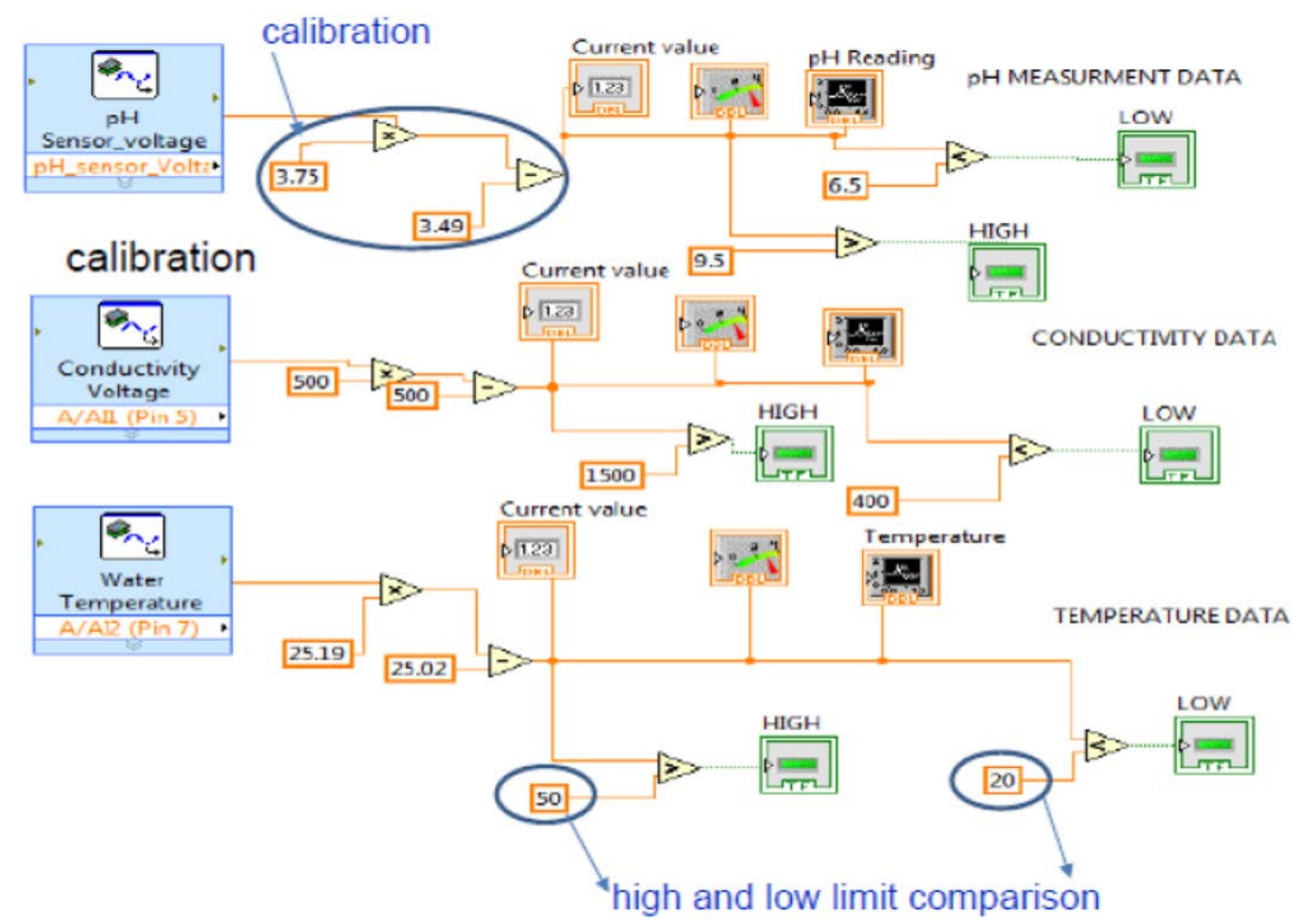

Figure 7: The LabVIEW level control block diagram of wireless system for water quality monitoring

For wireless communication system we use Wi-Fi technology. The Wi-Fi is one the industry standard of wireless network communication belonging to IEEE 802.11x family. It defines the MAC layer and physical layer. The physical layer defines two wireless frequency modulation modes and one infrared transmission mode, which work at the $2.4 \mathrm{GHz}$ license free ISM (Industrial Scientific and Medical) band. The Wi-Fi communication between two devices takes place on the basis of self-organizing network (i.e, Ad Hoc). The same can also be carried out under the coordination of the base station or access point. The Wi-Fi also supports a data rate of $11 \mathrm{Mbps}$. We use NI MAX measurement and automation explorer to configure IEEE 802.11 Wi-Fi connection with the NI myRIO microcontroller. The other main features of IEEE 802.11 are: high rate and high reliability. The communication distance is up to 100 meters in open space. But the same varies from 10-50 in indoor environment [17]. 
Another advantage of IEEE 802.11 is that it can be conveniently integrated with an existing wired Ethernet. The cost of IEEE 802.11 is low and it also possesses wired equivalent privacy to ensure the network security.

\section{Calibration and Data Analysis}

In order to ensure reliability and accuracy we calibrate the sensors. We use two types of calibration namely (a) sensor calibration, and (b) user front panel calibration.

\subsection{Sensors Calibration}

For $\mathrm{pH}$ sensor calibration we follow the same procedure mentioned in the manufacturer's operation and maintenance manual. Buffer solutions of $\mathrm{pH} 4.0$ and $\mathrm{pH} 7.0$ are used to carry out the two-point $\mathrm{pH}$ calibration according to manufacturer instructions (User Manual: pHDsc Digital Differential pH/ORP SensorsDOC023.52.03251). For conductivity sensor we use 'zero-point calibration' that is done by keeping the sensor air free. We also did the span calibration by using buffer solution of $2000 \mu \mathrm{S}$ according to the calibration procedure mentioned in the operation and maintenance manual (GLI 3700 series Inductive Electrodeless Conductivity Sensors User ManualDOC023.97.80079).

\subsection{User Front panel calibration}

Measurement, display, data logging, and analysis are the core components of our system. The performance of our system highly depends on accuracy of the data collected and processed. The output signals received from $\mathrm{pH}$, conductivity, and temperature sensors are linear and are of analog type. These sensors generate a current in the range of 4-20 mA. This 4-20 mA current signal is then converted into 1-5 V signal using a $250 \Omega$ standard resistance. To display and record this analog data in the front panel of the LabVIEW program we build a linear equation by using different values of output data (volts) vs display data (indicating value) for $\mathrm{pH}$, conductivity, and temperature. We calibrate the voltage range (i.e., 1-5 V) to the display values of $\mathrm{pH}$, conductivity, and temperature. We derived some equations by using Microsoft Excel program. These procedures are illustrated in Figure 8, Figure 9, and Figure 10.

\begin{tabular}{|c|c|}
\hline Volts (V) & $\mathrm{pH}$ \\
\hline 0.94 & 0 \\
\hline 1.47 & 2 \\
\hline 2.01 & 4 \\
\hline 2.55 & 6 \\
\hline 3.09 & 8 \\
\hline 3.61 & 10 \\
\hline 4.16 & 12 \\
\hline 4.90 & 14 \\
\hline
\end{tabular}

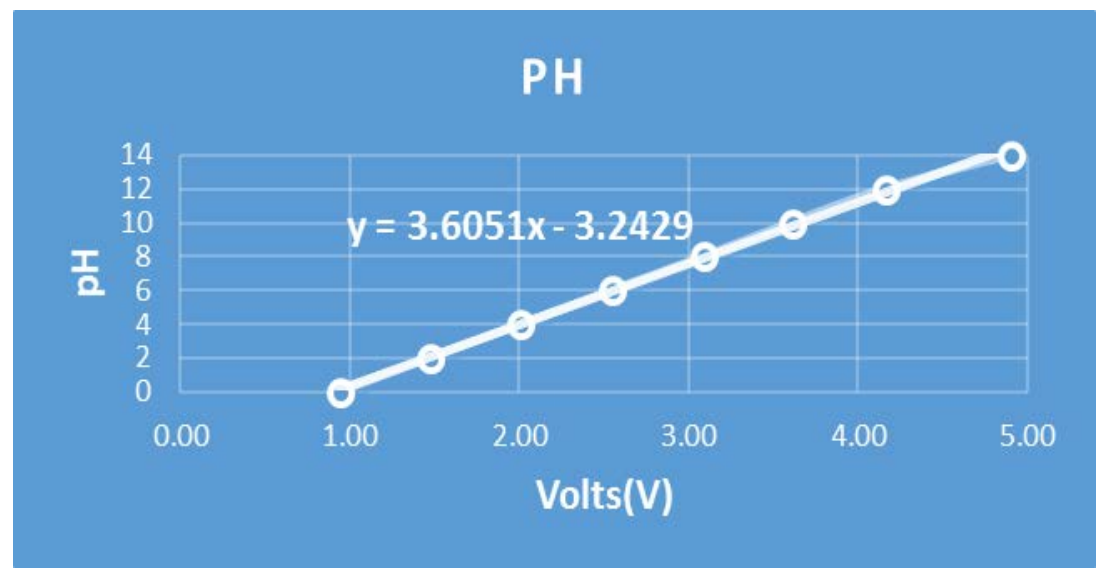

Figure 8. The pH equation for LabVIEW front panel display calibration. 


\section{Macrothink}

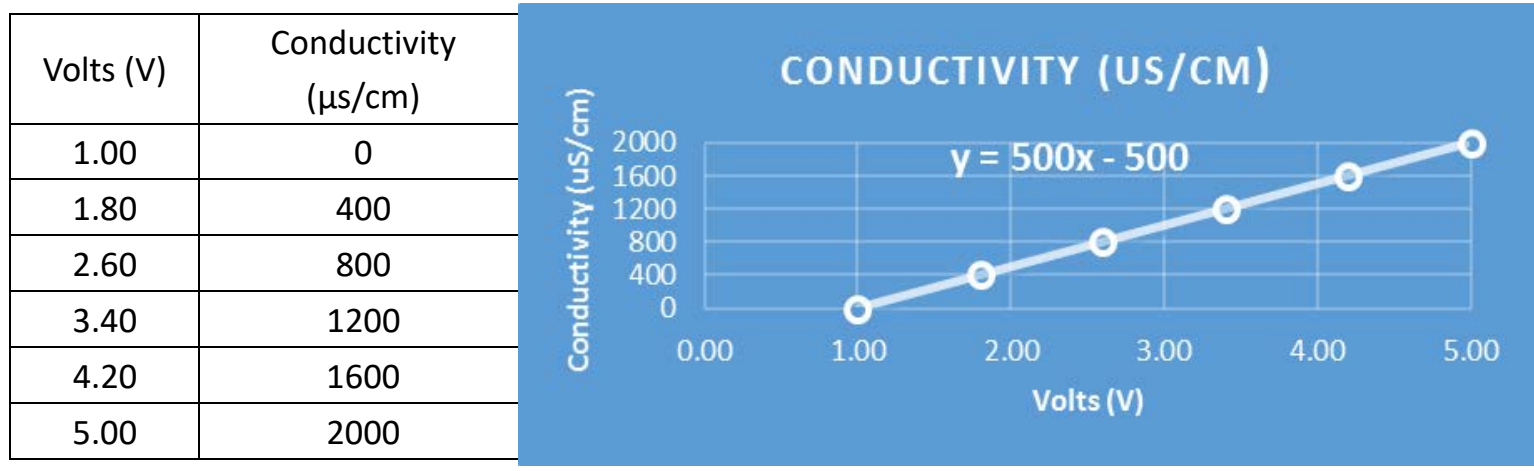

Figure 9. Conductivity equation for LabVIEW front panel display calibration.

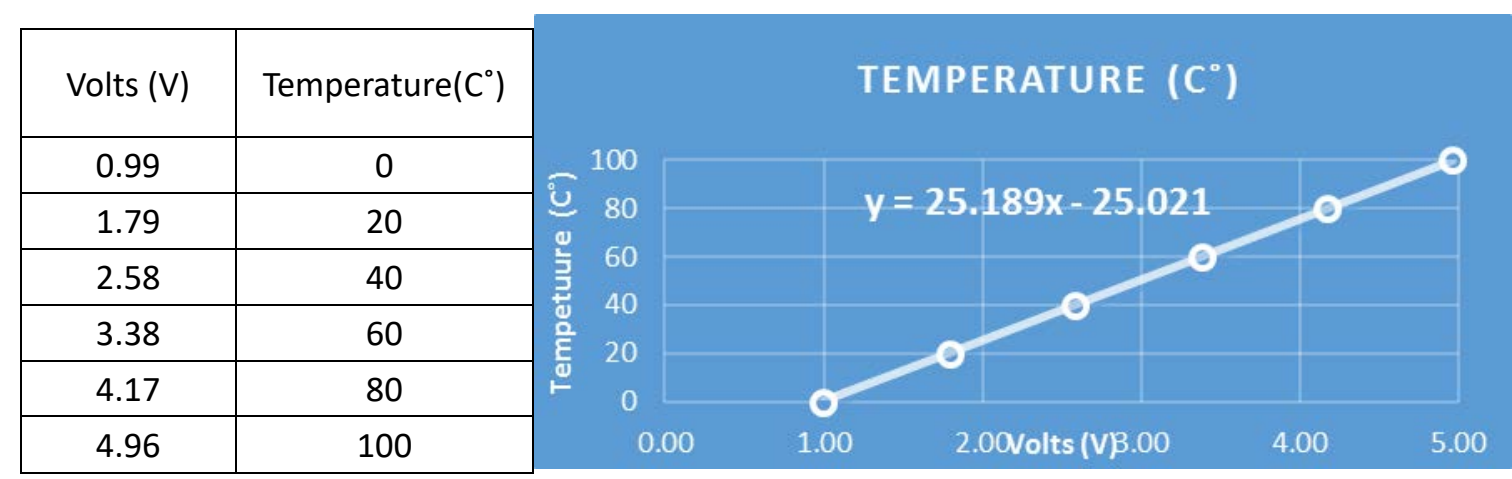

Figure 10. Temperature equation for LabVIEW front panel display value calibration.

The LabVIEW program can save this data in excel sheets. The data generated by the system can be shared among local bodies and government authorities, who can use these data water quality control and management. The system also creates chart and graphs to investigate the quality trends and to assess the water quality throughout the year.

Some of the charts based on the $\mathrm{pH}$, conductivity, and temperature are shown in Figure 11, Figure 12, and Figure 13. It is depicted in Figure 11 that the $\mathrm{pH}$ of water is almost constant at 8.8 till 11:45 a.m. The same rises to 10.00 at 12:15 p.m. Figure 12 and Figure 13 show that the conductivity and temperature of water always varies with respect to time. It is shown in Figure 12 that the conductivity varies between $1450 \mu \mathrm{S} / \mathrm{cm}$ and $1325 \mu \mathrm{S} / \mathrm{cm}$. On the other hand, the temperature varies between $28^{\circ} \mathrm{C}$ and $33^{\circ} \mathrm{C}$ as shown in Figure 13. 


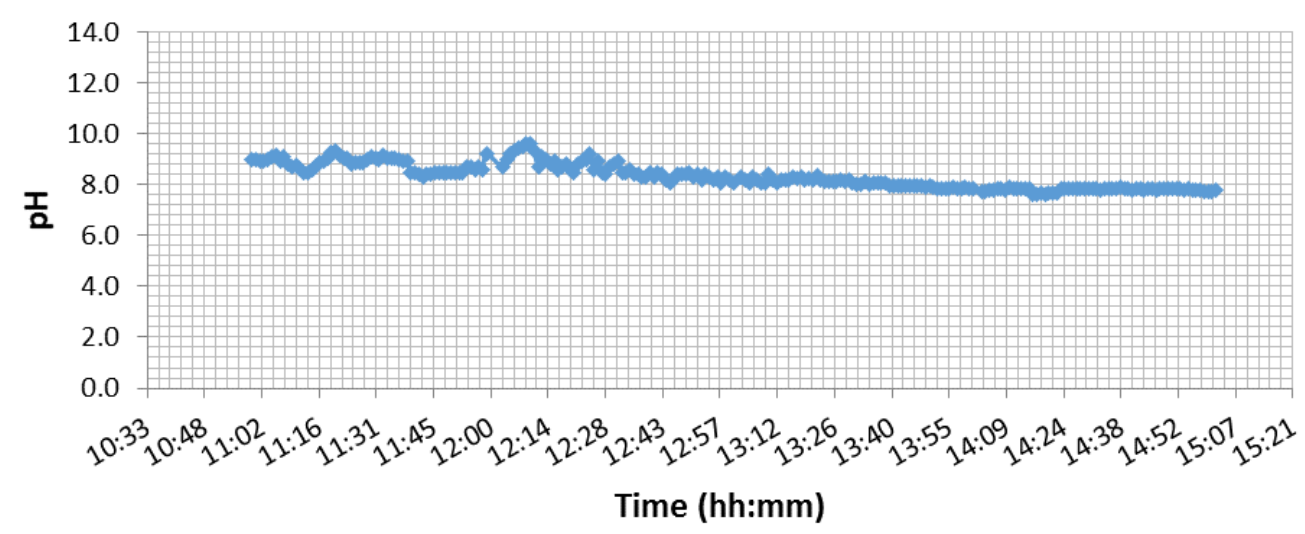

Figure11. The $\mathrm{pH}$ variation over time for local municipal water.

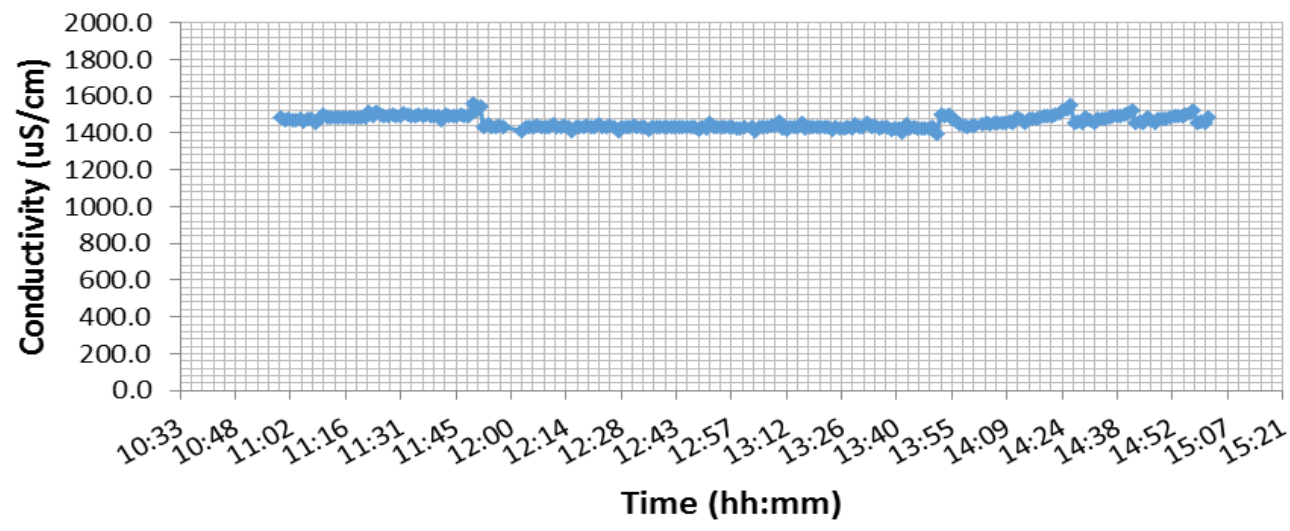

Figure 12. The conductivity variation over time for municipal water.

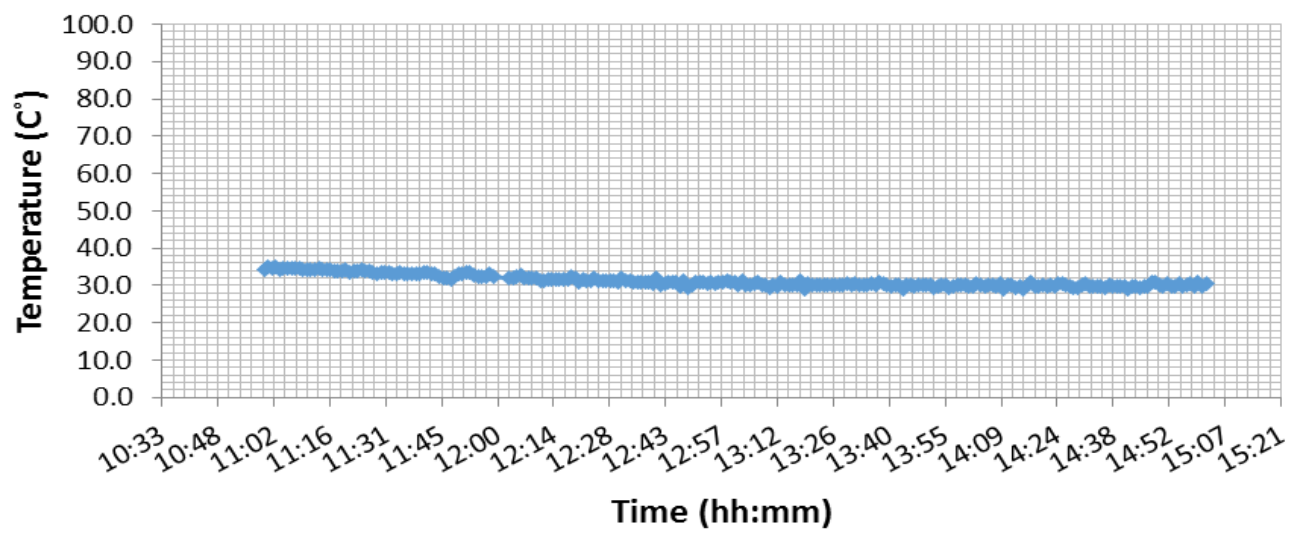

Figure 13. The temperature variation over time for municipal water.

\section{Conclusion}

In this paper we present a wireless system for water quality monitoring. In this system we integrate sensors, transmitters, receivers, myRIO microcontroller, and IEEE 802.11 Wi-Fi 
technology. In order to ensure high accuracy, we use industry standard sensors to measure water quality. Moreover, we also calibrate both the sensors and the system to ensure high reliability. A LabVIEW program has been developed for front panel display and for interfacing with the sensors. The system supports 24-hour real-time water quality monitoring. The user can control the system through the Internet. Hence, one can monitor the water quality by a mobile device from a remote site. Our system supports data management, analysis and statistics. The system also generates reports. The results show that our system can monitor the water quality with a high accuracy.

\section{Future Works}

In present system more sensors like turbidity and chlorine analyzer will be added to monitor and control the haziness and biological growth. System will be built by using the Advantech RTU ADAM 3600 microcontroller, which has 3G / 4G wireless broadband built in communication capability. System will be capable of handling more data at wider range and multiple sites can be linked together. The major limitation of the system is high cost. Since a local company supplied the equipment, we did not consider cost in our system design. Some low cost sensors have been presented in [18]. Similar low cost sensors have been used in a similar project presented in [19]. In our future work we will consider similar low cost sensors in our system instead of industry standard sensors.

\section{Acknowledgement}

We would like to acknowledge VEOLIA Water Technoligies, Fujairah, United Arab Emirates for supplementing sensors, transmitters, and calibration equipment.We would also like to thank the employees of VEOLIA Water Technologies for their encouragements and and supports during the implementation phase of this project.

\section{References}

[1] Progress on Drinking Water and Sanitation, Update and MDG Assessment, 2015, available at http://www.who.int/water_sanitation_health/

[2] Facts About Water and Sanitization available at http://water.org/water-crisis/water-sanitation-facts/

[3] World Economic Forum. Global Risks 2015 Report, 2015 available at: http://www3.weforum.org/docs/WEF_Global_Risks_2015_Report15.pdf

[4] John Lin, “Application of ZigBee Technology”. Available at http://gsi.nist.gov/global/docs/mra/2005_Lin_ZigBee.pdf

[5] H. Ceong, J-S. Park, and S. Han, "IT convergence application system for eco aquafarm," Proceedings of the IEEE Frontiers in the Convergence of Bioscience and Information Technologies, Jeju City, pp. 878-883. October 2007 http://dx.doi.org/10.1109/FBIT.2007.75

[6] S. Han, Y. Kang, K. Park, and M. Jang. "Design of environment monitoring system for aquaculture farms", Proceedings of the IEEE Frontiers in the Convergence of Bioscience and Information Technologies , Jeju 
City, pp. 889-893, October 2007 http://dx.doi.org/10.1109/FBIT.2007.77

[7] Y. Shifeng, K. Jing, and Z. Jimin, "Wireless monitoring system for aquaculture environment," Proceedings of the IEEE International Workshop on RF Integration Technology, Singapore, pp. 274-277, December, 2007 http://dx.doi.org/10.1109/RFIT.2007.4443969

[8] S. Sharudin Mohd, "Intelligent Aquaculture System via SMS", University of Teknology. Petronas, Malaysia, 2007.

[9] N. Samiha Haron, M. Khuzaimi Mahamad, I. Abdul Aziz, and M. Mehat, "Remote Water Quality Monitoring System using Wireless Sensors”, $8^{\text {th }}$ WSEAS International Conference on Electronics, Hardware, Wireless, and Optical Communications, Cambridge, UK, pp. 148-154, February 2009. Available at http://www.wseas.us/e-library/conferences/2009/cambridge/EHAC/EHAC24.pdf

[10] ZulhaniRasin and Mohd Rizal Abdullah, "Water Quality Monitoring System Using ZigBee Based Wireless Sensor Network”, International Journal of Engineering \& Technology (IJET), Vol. 9, No. 10, pp. 14-18, December 2009 available at http://ijens.org/91410-7575\%20IJET-IJENS.pdf

[11] A. Amit Joshi, "Water Quality Monitoring System Using Zig-Bee and Solar Power Supply”, International Journal of Advanced Research in Electrical, Electronics and Instrumentation Engineering, Vol. 4, No. 10, pp. 8103-8109, October 2015 http://dx.doi.org/DOI: 10.15662/IJAREEIE.2015.0410008

[12] R. Bhandare, M. Chhajed, S. Sonavane, "Water Quality Monitoring System”, International Journal of Engineering and Technical Research (IJETR), Vol. 3, No. 4, 97-100, April 2015 available at https://www.erpublication.org/admin/vol_issue1/upload\%20Image/IJETR031874.pd

[13] P. Jiang, H. Xia , Z. He , and Z. Wang, "Design of a Water Environment Monitoring System based on Sensor Networks”, Sensors, Vol. 9, pp. 6411-6434, August 2009 http://dx.doi.org/10.3390/s90806411

[14] R. Yue and T. Ying, "A Novel Water Quality Monitoring System Solar Power Supply and Wireless Sensor Network”, International Conference of Environmental Science and Engineering, Bali Island, Indonesia, Vol. 12, Part A, Pp. 265-272, 2012. ht://dx.doi.org/doi:10.1016/j.proenv.2012.01.276

[15] A. J. Whittle, M. Allen, A. Preis and M. Iqbal, "Sensor Networks for Monitoring and Control of Water Distributed System”, 6th International Conference on Structural Health Monitoring of Intelligent Infrastructure, Hong Kong, Pp. 1-13, December 2013. At http://dspace.mit.edu/handle/1721.1/92764

[16] Alexandros Zografos, “Wireless Sensor-based Agricultural Monitoring System”, Master thesis, KTH Royal Institute of Technology, Sweden, 2014 available at http://people.kth.se/ maguire/DEGREE-PROJECT-REPORTS/140325-Alexandros.Zografos-with-cover.pdf

[17] Introduction to WiFi available at http://ccm.net/contents/802-introduction-to-wi-fi-802-11-or-wifi

[18]Manjakkal, L., Cvejin, K., Kulawik, J., Zaraska, K., and Szwagierczak, D, “A low-cost pH sensor based on RuO2 resistor material”, Nano Hybrids, Vol. 5, pp. 1-15, October 2013. http://dox.doi.org/10.4028/www.scientific.net/NH.5.1

[19] Parra, L., Sendra, S., Lloret, J., \& Rodrigues, J. J., "Low cost wireless sensor network for salinity monitoring in mangrove forests", Proceedings of IEEE Sensor, Valencia, Spain, November 2014. http://dx.doi.org/doi:10.1109/ICSENS.2014.6984949

\section{Copyright Disclaimer}

Copyright reserved by the author(s).

This article is an open-access article distributed under the terms and conditions of the Creative Commons Attribution license (http://creativecommons.org/licenses/by/3.0/). 